\title{
Contribuciones de la sociología y la antropología para la comprensión del fenómeno religioso: una lectura en clave semiótica
}

\author{
Jorge Brower Beltramin ${ }^{1}$
}

\begin{abstract}
Resumen
Los aportes teóricos y metodológicos desarrollados por la sociología y la antropología para la comprensión del fenómeno religioso y su relevancia en la dinámica de las culturas, constituyen un referente insoslayable en la praxis analítica llevada a cabo desde la semiótica. El presente artículo expone la lectura de un conjunto discursivo perteneciente a autores destacados en la fundación y desarrollo de la sociología y la antropología, enfatizando la concepción simbólica y por tanto sígnica que atribuyen a la expresión figurativa de lo religioso.
\end{abstract}

Palabras clave: Religión, Signo, Construcción simbólica, Semiótica.

\begin{abstract}
The theoretical and methodological contributions developed by sociology and anthropology for the understanding of the religious phenomenon and its relevance in cultural dynamics, constitute an unavoidable referent in the analytical praxis carried out from semiotics. The present article exposes the reading of a discursive set belonging to renowned authors in the foundation and development of sociology and anthropology, emphasizing the symbolical conception and therefore signical that they attribute to the figurative expression in the religious.
\end{abstract}

Key words: Religion, Sign, Symbolical construction, Semiotics

1 Chileno. Académico Jornada Completa de la Facultad Tecnológica de la Universidad de Santiago de Chile. Licenciado en Educación mención Castellano (USACH), Magíster Artium en Literatura (USACH). Doctor en Estudios Americanos con mención en Pensamiento y Cultura (USACH), Área de especialización: Semiótica de la Cultura. Correo electrónico: jbrower@usach.cl 
Contribuciones de la sociología y la antropología para la comprensión del fenómeno religioso: una lectura en clave semiótica - Jorge Brower Beltramin

\section{Presentación}

En este artículo expondremos los aportes que hacen fundamentalmente la sociología y la antropología, respecto a una comprensión de la religión entendida desde una perspectiva semiótica, como un sistema de significación esencial para el desarrollo de las culturas. A partir de esta perspectiva disciplinar, la religión aparece como una estructura de sentido compleja articulada en contextos socioculturales específicos que validan y orientan un conjunto relevante de prácticas comunicativas al interior de una sociedad. Al delimitar esta clave de lectura, el conjunto de aportes provenientes de la sociología y la antropología en torno a la religión permite enriquecer posibles lecturas y análisis semióticos formales, cooperando con una aproximación explicativa que, aun cuando no se detiene de manera definitiva en la materialidad discursiva-narrativa propia del ámbito religioso, nos entrega un relato que otorga mayor densidad semántica a los análisis.

Esta selección de aportes no es casual ni arbitraria. Obedece más bien a que estas disciplinas, desde su fundación y a lo largo de su desarrollo, han elaborado una concepción semiótica no sólo de la religión sino también de la cultura. De este modo, constataremos más adelante, que tanto las posturas positivistas como las constructivistas dentro de la sociología y la antropología han expuesto la necesidad de analizar el fenómeno religioso a partir de su dimensión semántica-comunicativa. En consecuencia, más allá de los logros teórico-metodológicos alcanzados por estas disciplinas (en cuanto al análisis de la religión entendida como sistema discursivo-simbólico), nos interesa su producción de conocimiento ya que enriquece semánticamente cualquier aproximación analítica generada en el ámbito teórico-metodológico de la semiótica que intente describir las variables estructurales y contextuales respecto a corpus discursivos sobre religión. Dicha producción de conocimiento explica las múltiples dimensiones del sentido que dan cuenta de la trama discursiva religiosa, aportando de esta forma una comprensión más global respecto a esta 
manifestación simbólica compleja y trascendente para el desarrollo de las culturas.

\section{Contribuciones a partir de la obra fundacional de E. Durkheim.}

Sin duda, las explicaciones sociológicas sobre la religión, aportadas por Durkheim, representan un referente teórico y reflexivo insoslayable. Sus aportes, se inscriben en el marco epistemológico positivista ${ }^{2}$, desde el cual la religión aparece comprendida en su dimensión social, tratando de establecer en torno a ella, sus funciones más relevantes para la articulación global de una comunidad humana.

Durkheim inicia sus reflexiones teóricas señalando que la esencia de las representaciones colectivas o sistema de creencias de las comunidades ágrafas es esencialmente religiosa. En tal sentido, el autor señala que originalmente: “(...) la religión lo impregnaba todo; todo lo social era religioso, los dos ámbitos eran sinónimos." (DURKHEIM, 1982: p. 169). Esta situación, en la que la religión funcionaba como organizadora de la vida en comunidad, comienza a desaparecer, en la medida en que las sociedades evolucionan en sus formas de organización y administración. En este proceso evolutivo, agrega que en el desarrollo de "(...) la economía política y las funciones científicas éstas se liberaron de las funciones religiosas, se consolidaron por separado y tomaron cada vez más un carácter reconocidamente temporal". (DURKHEIM, 1982: p. 169). Como consecuencia de este desarrollo o evolución, el lugar que ocupaba un ser superior o dios va desapareciendo para dar paso a la creación de estructuras sociales que se hacen cargo del destino de las sociedades.

2 E Durkheim es considerado un heredero del pensamiento positivista inaugurado por A. Comte. Este contexto teórico-epistemológico, desde el cual Durkheim realiza sus aportes sociológicos, es muy relevante ya que la perspectiva positivista sobre el conocimiento, entiende dicho conocimiento como positivo, es decir, como un saber empírico que rechaza toda forma de pensamiento metafórico por considerarlo sofista o ilusorio. Para el positivismo, sólo las afirmaciones sujetas a verificación empírica serán comprendidas como válidas. 
Contribuciones de la sociología y la antropología para la comprensión del fenómeno religioso: una lectura en clave semiótica - Jorge Brower Beltramin

A partir de estas consideraciones iniciales este sociólogo elabora lo que conocemos como teoría durkheimiana de la religión ${ }^{3}$.

En su clásico estudio de 1915, Las formas elementales de la vida religiosa, este padre fundador de la sociología se aboca a comprender lo que él llama "(...) principios omnipresentes en las formas más elementales del pensamiento religioso" (Durkheim, 1982: p. 18). Para tal efecto, sus trabajos se orientan a estudiar la religión en sus formas más simples y primitivas sin pretender dar cuenta de la veracidad o falsedad que esos contenidos culturales contienen. La religión es tratada desde su perspectiva teórica como un conjunto de clasificaciones sobre todas las cosas, sean éstas reales o ideales en dos clases distintas, las profanas y las sagradas. A partir de dicha reflexión, propone su conocida definición de religión, entendida como "(...) un cuerpo de prácticas y creencias relativas a las cosas sagradas, es decir, todo aquello que se identifica con las cosas dejadas de lado y prohibidas-creencias y prácticas que dan unidad a una comunidad moral concreta." (Durkheim, 1982: p. 37).

En esta definición es posible detectar aportes interesantes que serán retomados con posterioridad por otros investigadores sobre este tema específico. Lo sagrado aquí, aparece relacionado

3 Los postulados que dan forma a la teorización sobre la religión, desarrollados por Durkheim, fueron influenciados de manera importante por los trabajos de Fustel De Coulanges y de W. Robertson-Smith. El primero de ellos, en su estudio clásico, La ciudad Antigua, se preocupa de las relaciones entre la religión y la vida social en el contexto de la Antigüedad Clásica. Este autor sostiene que las ideas religiosas constituyen las causas fundamentales de los fenómenos sociales y sus cambios. Cf. De Coulanges, The Ancient City: A Study of the religion, Laws and Institutions of_Greece and Rome, Londres, Lee and Sheperd, 1900, pp. 11-12.

El otro autor que ya señalamos como influyente en la teoría sociológica de la religión desarrollada por Durkheim, es W. Robertson-Smith, quien en su estudio más importante sobre este tema, The Religion of the Semites, plantea la importancia de los rituales por encima de las creencias, en las religiones primitivas. Para RobertsonSmith estas religiones (primitivas y ágrafas) se definen por el ejercicio de sus rituales y el saber práctico, más que por un esfuerzo de comprensión sobre la naturaleza de los seres superiores o dioses. Para este autor, los rituales tenían una función social de convocatoria y unión de los integrantes de una comunidad. Cf. W. Robertson-Smith, The Religion of the Semites, Edimburgo, Block, 1900, p. 20 y ss. 
con el conjunto de creencias en lo sobrenatural practicadas en una comunidad determinada. Por otro lado, y esto es lo que a nuestro juicio resulta más iluminador, la religión representa una función social por medio de la cual la comunidad es convocada. El colectivo social se unifica, toma forma e identidad mediante la práctica de las creencias religiosas. La religión en Durkheim entonces, no puede ser separada de la práctica de un culto comunitario.

Dentro de esa concepción del fenómeno religioso, este sociólogo francés comienza a dar algunas claves que nos parecen relevantes de ser rescatadas desde una lectura en clave semiótica. En efecto, para Durkheim, el conjunto de elementos que dan forma a lo sagrado o creencia es de naturaleza simbólica, y por tanto, toda la investigación sobre la religión debe orientarse a la identificación y comprensión de los referentes contenidos en ese sistema simbólico. Una religión es entonces y antes que todo, un sistema de expresión simbólico. En esa dimensión la conocemos, y sus estructuras profundas sólo pueden explicarse desde esta dimensión expresiva. En esa línea de reflexión teórica, Durkheim da un paso más, señalando que dentro de este sistema simbólico que da cuenta de la religión, las formas míticas y rituales tienen un papel fundamental. Ambos elementos poseen un carácter básicamente semiótico. Toda la concepción religiosa de la vida radica en las formas míticas que no son más que estructuras narrativas orientadas principalmente a explicaciones teleológicas de la existencia y al desarrollo de cosmogonías directamente relacionadas con la vida de una comunidad o cultura.

Estas observaciones introducen las reflexiones durkheimianas dentro de un territorio puramente semiótico y abarcan simultáneamente la dimensión discursiva o del relato y la dimensión contextual. Tanto la estructura narrativa mítica como la expresión ritual a las cuales se les atribuía poderes sobrenaturales y que representaban a héroes o ancestros se encuentran producidos mediante un complejo sistema de signos trascendentes y eleva- 
dos a la categoría de símbolos, mediante los cuales las comunidades primitivas fijaban el destino de sus vidas individuales y colectivas. La religión como fenómeno cultural integral aparece en este contexto teórico como un componente de significado fundamental en la vida de las sociedades primitivas. El complejo sistema semiótico que la expresa (a la religión), es antes que todo una representación de los individuos de sí mismos dentro de la sociedad de la que ellos son miembros integrantes.

Con esta explicación, busca eliminar la dimensión metafísica de la religión, para situarla en el plano puramente funcional dentro de la organización de la vida social. El propio investigador señala que "Dios no es otra cosa que una expresión figurativa de la sociedad". (Durkheim, 1982: p. 226).

A partir de la obra de Durkheim, las investigaciones, tanto teóricas como de reconocimiento en terreno, realizadas por Mauss, ocupan un lugar de privilegio. Considerado como el discípulo más aventajado de Durkheim, Mauss se mueve con habilidad entre los ámbitos reflexivos propios de la sociología y la actividad de descripción y comprensión de estructuras culturales primarias, desde una perspectiva antropológica.

Mauss hereda de su maestro, la perspectiva simbolista que Durkheim había tomado para la comprensión de la organización de las sociedades primitivas, dentro de la cual la religión ocupa un lugar de gran importancia para la articulación coherente de los grupos humanos y la formación expresiva de una identidad cultural definida. Dicha perspectiva simbolista es asumida por Mauss en variados pasajes de su obra, mostrando una marcada conciencia semiótica respecto a los fenómenos sociales en su conjunto. En este sentido, señala que una de las características fundamentales del hecho social "(...) es precisamente su aspecto simbólico. En la mayor parte de las representaciones colectivas, no se trata de una representación única de una cosa única, sino de una representación arbitraria, o más o menos arbitraria, que 
significan otras o que suponen unas costumbres" (Mauss, 1991: p. 277).

Con esta afirmación, Mauss se acerca de manera sorprendente a la definición lingüística del signo, propuesta por F. De Saussure. Para Mauss, las representaciones sociales constituyen, antes que todo, una manifestación arbitraria, cuyo contenido se define culturalmente. En términos de Saussure, lo señalado por Mauss tiene que ver con el carácter arbitrario del signo lingüístico, en donde la relación entre expresión y contenido se establece mediante convenciones propuestas por una comunidad de hablantes. Entender esta característica básica de los sistemas simbólicos, permite “(...) explicar importantes elementos de los mitos, de los ritos, de las creencias, de la fe en su eficacia, de la ilusión, de la alucinación religiosa y estética, de la mentira y del equilibrio colectivo de sus correctivos" (Mauss, 1991: p. 277).

La comprensión de la naturaleza simbólica de todos los sistemas sociales, dentro de los cuales Mauss ubica a la religión y las creencias en general, significa asumir una perspectiva gnoseológica de carácter semiótico para la descripción de la cultura en su integridad. En efecto, este teórico se sintió profundamente atraído por los avances de la lingüística, entendida como el desarrollo de una metodología con sólido sustento conceptual que permite analizar la materialidad semántica de los sistemas simbólicos, comprendiendo así el sentido más profundo desde el cual se generan.

Quien recoge con mayor lucidez la conciencia semiótica de Mauss para la comprensión de la cultura y dentro de ella, de los sistemas religiosos, es C. Lévi-Strauss. Considerado padre de la antropología estructural (llamada también semántica estructural), Lévi-Strauss señala que Mauss, al plantear estas preocupaciones respecto a la naturaleza simbólica de las diversas expresiones culturales, adelanta lo que serán los temas centrales de la antropología más actual, que precisamente se orientan a la des- 
cripción de la cultura entendida como un fenómeno semiótico. Lévi-Strauss hace notar que el aporte de Mauss se centra en la vida social como un mundo de relaciones simbólicas. En esta línea de reflexión “(...) la sociedad expresa sus costumbres y sus instituciones por medio de símbolos, mientras que las conductas individuales, (...) son los elementos a partir de los cuales se construye el sistema simbólico, que únicamente puede ser colectivo." (Mauss, 1991: p.18).

La lectura de Lévi-Strauss recoge un conjunto de reflexiones maussianas que dan cuenta de una comprensión de la cultura que ya estaba instalada en el pensamiento de Durkheim. La representación simbólica de la sociedad en su conjunto da cuenta del sentido colectivo de ésta, siendo los miembros de una colectividad, entendidos como grupo estructurado, la base desde la cual se genera la materialidad simbólica que expresa una cultura y una identidad. Lévi-Strauss profundiza en su lectura sobre Mauss, acotando el concepto de cultura entendida como "(...) un conjunto de sistemas simbólicos que tienen situados en primer término el lenguaje, las reglas matrimoniales, las relaciones económicas, el arte, la ciencia y la religión." (Mauss, 1991: p. 20). Esta concepción de la cultura y dentro de ella de la religión, se acerca notablemente a la visión semiótica sobre cualquier fenómeno cultural. Efectivamente, a nuestra investigación le interesa el análisis de ciertas estructuras semánticas de naturaleza religiosa y también las diferentes vinculaciones que dichas estructuras semánticas generan con otras estructuras de sentido presentes en el entramado social en las expresiones simbólicas de una cultura.

De este modo, Mauss asume la posición simbolista, como hemos señalado antes, heredada de Durkheim, dando un paso hacia la apertura a otras disciplinas, en particular la lingüística, cuya cooperación al campo investigativo propio de la sociología y la antropología, genera la posibilidad de conocer los sistemas simbólicos desde su materialidad semántica. 
Sin embargo, la intencionalidad teórica de Mauss, no pasa de ser la enunciación de un proyecto de desarrollo para la sociología y la antropología. Los trabajos en terreno asumidos por este investigador, en relación al comportamiento de las sociedades primitivas, seguirán el camino de un empirismo muy elemental en el que se busca señalar y describir las acciones prácticas, propias de las costumbres e instituciones de una sociedad.

En síntesis, los aportes de Mauss son notables en dos sentidos concretos. Por un lado, retoma las inquietudes analíticas de Durkheim, asumiendo la perspectiva simbolista de éste, respecto a las diversas prácticas culturales. Este aspecto es importante, ya que dentro de esas prácticas se encuentra la religión, que desde esta postura se entenderá básicamente como una expresión simbólica cuyo fin fundamental es la cohesión de una comunidad en torno a una identidad propia.

Por otra parte, intenta aproximarse a una comprensión más cabal de estos sistemas simbólicos, dejando trazada la ruta por la que debiera avanzar la sociología y la antropología. Sin duda, la opción que propone Mauss, tiene que ver con la necesidad de conocer las técnicas operatorias y analíticas desarrolladas por la lingüística dentro de la tradición saussuriana. Este punto nos parece particularmente relevante ya que es el análisis lingüístico, a través de sus metodologías específicas, la que permitirá, en trabajos posteriores a los de Mauss (nos referimos especialmente a la obra de C. Lévi-Strauss), conocer efectivamente la materialidad significante de los sistemas simbólicos, dentro de los cuales el lenguaje religioso realiza una función determinante para la configuración de los grupos sociales, la articulación de las culturas y la definición de identidades particulares.

En la misma línea de análisis simbolista inaugurada por Durkheim y desarrollada por Mauss, los trabajos de Lévi-Bruhl representan un intento por explicar el origen de las manifestaciones simbólicas, es decir, la o las modalidades de pensamiento que 
Contribuciones de la sociología y la antropología para la comprensión del fenómeno religioso: una lectura en clave semiótica - Jorge Brower Beltramin

se ponen en práctica para producir una determinada estructura simbólica, siempre en el contexto de las sociedades primitivas, y preferentemente ágrafas. Con esta intención investigativa inicial, los trabajos de Lévi-Bruhl son considerados como los fundadores más recientes de la línea antropológica de orientación semiótica y estructuralista. ${ }^{4}$

La observación inicial de este autor, para entrar al estudio de las sociedades primitivas, es que éstas funcionaban mediante un pensamiento muy diferente al de las sociedades europeas, y por tanto no era válido aplicar las categorías analíticas occidentales a dichas sociedades primitivas, ya que esa aplicación sólo lograría distorsionar las formas de pensamiento y por tanto la mentalidad con la que los primitivos organizaban su existencia en comunidad.

La primera definición importante desarrollada por LéviBruhl respecto del pensamiento primitivo se refiere a que éste es fundamentalmente místico. Es necesario aclarar lo que este autor entiende por místico, ya que en el contexto de sus trabajos, difiere en gran medida de lo que nosotros entendemos por este concepto. Lo místico, dentro de los trabajos de Lévi-Bruhl, se relaciona con una forma de ver o percibir el mundo que no es natural, sino que está regulada por un conjunto de creencias en entidades sobrenaturales. Según este autor esto no significa que los pueblos

4 L. Lévi-Bruhl desarrolla la perspectiva simbolista inaugurada por Durkheim y continuada por Mauss, tratando de dar cuenta de las estructuras mentales más profundas que se ponen en acción, para articular un determinado sistema de símbolos.

Este trabajo se ve enriquecido por los aportes de Evans-Pritchard quien, en la misma línea de investigación, intenta dar un paso explicativo más, señalando que el análisis sociológico y antropológico debía situarse en última instancia, en las estructuras que subyacen a una sociedad o cultura, siendo estas estructuras de naturaleza sígnica y por tanto semántica. Dichas estructuras, señala Evans Pritchard “(...) no aparecen a simple vista. Se componen de una serie de abstracciones, cada una de las cuales, aunque derivada del análisis del comportamiento observado, es el producto del trabajo de imaginación del propio antropólogo. Al relacionar lógicamente estas observaciones entre sí de forma que compongan un modelo, él puede ver la sociedad en sus elementos esenciales, como un todo." Ensayos de antropología social, Madrid, Siglo XXI, 1980, p. 23. 
ágrafos se encuentren en un estado de ignorancia, sino más bien, tiene que ver con una forma diferente de pensar el mundo y de concebir los elementos con los que está poblado. En los propios términos de Lévi-Bruhl, el pensamiento místico o actividad mental mística desde la cual las sociedades primitivas conciben el mundo, se refiere a "(...) la creencia en las fuerzas, en las influencias, en las acciones imperceptibles a los sentidos (...)" (Lévi-Bruhl, 1947: p. 34), desde las cuales estas comunidades organizan su vida.

De este modo, la realidad en la que viven los primitivos, “(...) es mística en sí misma. En sus representaciones colectivas, ningún ser, ningún objeto, ningún fenómeno natural es lo que parece ser."(Lévi-Bruhl, 1972: p. 30). Desde esta perspectiva, el pensamiento religioso se encuentra enraizado en la mentalidad mística de las primeras comunidades humanas, mentalidad altamente compleja que privilegia ciertas estructuras narrativas cuyos contenidos exponen un conjunto de creencias básicas para interpretar los sucesos de la cotidianidad, y también los acontecimientos más trascendentes como la vida y la muerte.

Dicho pensamiento místico instala una discursividad explicativa de la existencia cuya lógica o forma de funcionamiento se aleja de nuestra lógica causal para explicar los fenómenos que nos suceden en determinados contextos de vida.

Desde la perspectiva de Lévi-Bruhl, la explicación mística procurada por las sociedades primitivas, instaura una lectura distinta a la occidental respecto de los acontecimientos que suceden dentro de una sociedad determinada. Como señala el mismo autor, nada es lo que parece ser, o al menos sobre lo que parece ser se desarrolla otra lectura, otra interpretación que puede tensionar y finalmente destruir la explicación lógica desde la cual nosotros entendemos los sucesos que nos acontecen.

La identificación de este proceso, en relación a la forma que asume el pensamiento primitivo la explicación de la realidad, llevó a Lévi-Bruhl a plantear, para este tipo de mentalidad, lo que 
Contribuciones de la sociología y la antropología para la comprensión del fenómeno religioso: una lectura en clave semiótica - Jorge Brower Beltramin

denominó como ley de participación. Según esta ley “(...) el espíritu de los primitivos es poco sensible a la contradicción"(Lévi-Bruhl, 1947: p.36). Esto significa que la mentalidad primitiva, denominada como mística, se presenta neutra respecto del principio de no contradicción. Como señalábamos antes, en virtud de esta ley, los seres y los objetos pueden ser, en sus representaciones simbólicas, ellos mismos, pero simultáneamente otra cosa. ${ }^{5}$

El planteamiento de la ley de participación, permite a firmar a Lévi-Bruhl que el pensamiento primitivo es prelógico. Al respecto, Weinberg señala que "(...) si nosotros buscamos las causas mediatas de los sucesos, ellos se dan por satisfechos atribuyéndolas de inmediato y directamente a las potencias místicas; (...)." (Lévi-Bruhl, 1972: p. 10)

De este modo, la ley de participación propuesta por Lévi-Bruhl, adiciona a la condición mística presente en el pensamiento primitivo, un carácter prelógico. Para este investigador, la mentalidad de las sociedades que él llama "inferiores", no es ni antilógica ni es alógica, sino que se manifiesta como prélogica en tanto que no se limita, como en el pensamiento occidental, a abstenerse de la contradicción.

5 La ley de la participación propuesta por Lévi-Bruhl para caracterizar la forma de funcionamiento de la mentalidad primitiva y desarrollada por primera vez en Les functions mentales dans les sociétés inférioures (1910), da cuenta de un modo de pensamiento que coincide con la "paradoja de la heterologicidad", descrita por L. Nelson y K. Grelling en "Bemerkungen zu den Paradoxien von Russel und Buraliforti" (1907-1908). También conocida como "paradoja de Grelling", las expresiones heterológicas son las que no se refieren a sí mismas, de la forma: ' $t$ ' no es $t$. En donde ' $t$ ' se identifica con $t$ en primer término (autológico), pero a la vez es diferente de $t$ (heterológico). De este modo, en el pensamiento indígena, tal como lo ejemplifica Lévi-Bruhl, los elementos del mundo natural serían eso, un río, una montaña, un árbol, pero al mismo tiempo serían otra cosa, como dioses, fuerzas benignas o malignas, etc.

En consecuencia, el modo de funcionamiento de la mentalidad primitiva no es prelógico, sino que instaura una lógica simbólica diferente a la nuestra (heterológica), articulada sobre la base de un conjunto de creencias que en su calidad de relato, reordenan los elementos de la realidad, asignándoles cualidades distintas a las otorgadas desde la pura percepción a su dimensión material. En tal sentido, Lévi-Bruhl comete el error de señalar que los primitivos son "impermeables" a la experiencia. Por el contrario, las sociedades consideradas por este autor "inferiores", reconocen la realidad como un dato identificable en tanto que materialidad concreta. 
Los esfuerzos teóricos de Lévi-Bruhl giran básicamente en torno a la necesidad de explicar esta característica prelógica de las mentalidades primitivas, como consecuencia de un pensamiento que se articula y funciona desde lo que él llama ley de participación.

Los hábitos mentales de las sociedades primitivas, desarrollados desde su condición mística y prelógica, excluyen en su desarrollo un pensamiento más abstracto que, desde ciertas cualidades de la realidad, generen, como ya decíamos, un modelo explicativo de naturaleza causal de la propia realidad. Por el contrario, en las sociedades primitivas, la actividad prelógica de su pensamiento hace que los datos entregados por el entorno natural y también cultural sean entendidos a partir de la acción de espíritus invisibles y de fuerzas que no son palpables. Estas entidades sobrenaturales son para los primitivos "(...) las más reales. $\mathrm{Su}$ fe se expresa tanto en los actos más insignificantes como en los más importantes. Toda su vida, toda su conducta está impregnada de ellos."(Lévi-Bruhl, 1972: p. 34).

Así, la existencia de estas comunidades, aun cuando podían haber conocido mediante la experiencia las leyes propias de la naturaleza, tenía su sentido último en lo que los individuos que dan forma al mundo místico señalaban para cada instancia de la vida. Este mundo, desde el cual se desprenden todas las creencias de los hombres primitivos, elimina de manera radical, la necesidad de buscar relaciones y explicaciones causales respecto a los acontecimientos que se producen al interior de la comunidad. De este modo, cuestiones tan fundamentales como la muerte de uno de los miembros del grupo, no obedece a un proceso natural de deterioro físico y mental, sino a la intervención de las potencias místicas que, por un motivo particular, han decidido respecto del deceso de ese individuo. Lo mismo sucede con las enfermedades, los nacimientos, los accidentes, etc. ${ }^{6}$

6 Lévi-Bruhl recurre a una gran cantidad de ejemplos en relación a cómo funciona la mentalidad primitiva en diversos pueblos ágrafos. Entre ellos, y a propósito de la 
Contribuciones de la sociología y la antropología para la comprensión del fenómeno religioso: una lectura en clave semiótica - Jorge Brower Beltramin

Las creencias en estas potencias místicas generan, desde la perspectiva de Lévi-Bruhl, un conjunto de representaciones colectivas según las cuales el papel de las causas mediatas es despreciable, por ser la verdadera causa de los acontecimientos, de orden místico. Se produce de esta forma, una construcción de mundo que evidentemente no coincide con el nuestro. Dicho mundo no se articula a partir de las preguntas básicas que podemos hacerle al entorno natural, ya que este entorno es un dato secundario. Todas las preguntas posibles respecto al funcionamiento del mundo primitivo se encuentran respondidas de antemano, gracias al poderoso correlato místico en el que se encuentran todas las respuestas para la vida.

El pensamiento primitivo se organiza, como es posible observar, desde la dimensión mística, dentro de la propuesta teórica de Lévi-Bruhl. Esa dimensión mística, a su vez, da forma a una modalidad de pensamiento que, como ya señalamos, este autor denomina como prelógica y que en definitiva corresponde a una lógica diferente a la nuestra para comprender al hombre instalado en el mundo.

Desde una perspectiva semiótica, nos interesa rescatar el aporte de este antropólogo, ya que para él, los sistemas simbólicos corresponden a la expresión más visible de la experiencia mística. En el símbolo radica el conocimiento otorgado por la dimensión mística que rige la existencia de los hombres. Allí se encuentra hecha materialidad comunicativa, el misterio de la vida y de la muerte. Allí, en un complejo entramado de textualidad altamente simbólica, descansa el trazado que inevitablemente deberán seguir los miembros de una comunidad, de una cultura.

concepción de la muerte, el investigador cita un trabajo realizado por R. Latchman, en el que este último señala: "Entre los araucanos 'todas las muertes, exceptuando las ocurridas sobre el campo de batalla, son producidas por causas sobrenaturales o hechicería. Si una persona muere a consecuencia de un accidente violento, se supone que los huecuvus o espíritus malignos lo han provocado espantando su caballo para desmontar al jinete (...)". Lévi-Bruhl, La mentalidad primitiva, p. 42. Cf. R.E._Latchman, "Ethnology of the Araucanos". Journal of the Anthropological Institute of Great Britain, XXXIX, p. 364. 
En definitiva, las investigaciones de Lévi-Bruhl constituyen para nosotros un aporte de gran valor, ya que abordan por un lado la dimensión de la generación de las estructuras simbólicas (pensamiento prelógico) intentando explicar cómo funciona dicha dimensión y por otro lado, pone énfasis en la importancia de los sistemas simbólicos entendidos como la expresión del pensamiento primitivo, denominado místico y prelógico. Estas contribuciones representan un referente fundamental respecto a los aportes que nosotros haremos desde esta investigación, ya que en instancias posteriores de la tesis retomaremos el concepto de pensamiento prelógico para ser redefinido a partir de los resultados de nuestro análisis.

Más allá de que Lévi-Bruhl haya podido establecer bases teóricas sólidas respecto a estos dos fenómenos (formas de pensamiento prelógico y expresión simbólica), es indudable que su trabajo investigativo teórico y en terreno, significa un avance en el esfuerzo para visualizar y comprender los distintos componentes que dan cuenta de una cultura, dentro de la cual la religión o las prácticas religiosas aparecen como una actividad fundamental.

En esa línea de investigación y tomando como base los aportes de Durkheim, Mauss y el propio Lévi-Bruhl entre los más importantes, C. Lévi-Strauss, es el antropólogo que desarrolla un proyecto sólido de aproximación a la cultura en general y a las características que en particular asume en las comunidades primitivas.

La obra de Lévi-Strauss es el resultado de un conjunto de influencias y aportes personales, a partir de sus reflexiones teóricas basadas en el modelo lingüístico saussuriano. Sin duda, la preocupación de Mauss por la naturaleza simbólica de las culturas primitivas, y el intento por explicar la forma de funcionamiento de la mentalidad primitiva, realizado por Lévi-Bruhl, son asumidos en el trabajo investigativo de Lévi-Strauss. Este antropólogo da forma a una construcción disciplinar, en el contexto del para- 
digma estructuralista, para entender objetos de estudio como los mitos originarios y el propio pensamiento de las primeras culturas ágrafas. Desde esa perspectiva estructuralista, la hipótesis inicial de Lévi-Strauss es que detrás de las diversas prácticas empíricas de las sociedades humanas existe una unidad de fondo, una estructura profunda, a partir de la cual la mente humana organiza la realidad, expresándola finalmente en un sistema simbólico más o menos complejo. Aquí, el esfuerzo teórico straussiano se relaciona de manera importante con el trabajo de Lévi-Bruhl, ya que su interés final tiene que ver con la búsqueda de ciertas estructuras subyacentes de la mente humana, para describir cómo esas estructuras regulan el funcionamiento de las mentalidades primitivas. En otras palabras, Lévi-Strauss pretende formalizar a nivel teórico lo que Lévi-Bruhl había descrito en sus textos como pensamiento místico y prelógico.

Como heredero de la perspectiva simbolista inaugurada por Durkheim en la tradición francesa, Lévi-Strauss entiende los fenómenos sociales, antes que todo, como sistemas de comunicación, asignando a la antropología un carácter semiológico, teniendo como centro de estudio los procesos de significación.

A partir de esta premisa, la antropología lévi-straussiana toma un rumbo cualitativo, cuyo interés fundamental es la dimensión semántica de los procesos culturales, alejándose progresivamente de las descripciones más funcionales de dichos procesos, propias de investigaciones realizadas desde el paradigma positivista. Al igual que Mauss, Lévi-Strauss considera que todas las formas de intercambio dentro de una comunidad, importan por su valor simbólico y por la consiguiente conducta simbólica que esos intercambios producen.

Dentro de esa preocupación por el valor simbólico de los procesos culturales, los mitos y la religión adquieren un carácter fundamental, y por tanto, el desarrollo de su antropología semántico-estructural se orientará desde estos dos referentes de investigación. 
Los procesos y sistemas simbólicos corresponden, según Lévi-Strauss, a la dimensión expresiva de las estructuras profundas que se encuentran en los mitos y las religiones. Al respecto, el antropólogo señala: “(...) la actividad inconsciente de la mente consiste en imponer formas a los contenidos, y si estas formas son fundamentalmente las mismas para todas las mentes -antiguas y modernas, primitivas y civilizadas- es necesario y suficiente captar la estructura inconsciente que subyace en cada institución y en cada costumbre a fin de obtener el principio de interpretación válido para otras instituciones."(Lévi Strauss, 1992: p. 21).

Como señalábamos antes, para Lévi-Strauss, la estructura social profunda no tiene que ver con el conjunto de acciones y episodios empíricos que podemos observar, sino que más bien, se relaciona con modelos que son transversales a todas las sociedades. Hacia la descripción de esos modelos apunta su trabajo intelectual. La religión, o el componente religioso deberán comprenderse como uno de esos modelos de pensamiento expresado por cada cultura mediante un tipo de lenguaje específico.

De este modo, el pensamiento primitivo descrito metafóricamente por Lévi-Bruhl, es retomado por Lévi-Strauss, asignándole el nombre de pensamiento salvaje, denominación con la cual fue titulado uno de sus textos más célebres.

El pensamiento salvaje, propio de los pueblos ágrafos, representa para Lévi-Strauss, al igual que para Durkheim, un tipo de mentalidad anterior, lo que no significa que ésta sea inferior o prelógica, como la había descrito Lévi-Bruhl.

Desde la perspectiva de Lévi-Strauss, la estructura profunda del pensamiento salvaje no tiene que ver con una negación del mundo natural, como lo suponía Lévi-Bruhl, sino que por el contrario, implica un conocimiento muy acabado del mismo. Este conocimiento más los contenidos religiosos y míticos en general, socializados dentro de las comunidades, a través de diversas narraciones, representan la modalidad expresiva de los modelos o 
Contribuciones de la sociología y la antropología para la comprensión del fenómeno religioso: una lectura en clave semiótica - Jorge Brower Beltramin

estructuras de base a las que se pretende acceder, mediante la metodología proporcionada por la semántica antropológica. En este contexto teórico, la religión se establece como una forma de vinculación íntima con el mundo natural, entendida como uno de los códigos culturales que expresan la estructura más profunda del pensamiento salvaje o primitivo.

Inspirado en el análisis lingüístico de corte estructural saussuriano, Lévi-Strauss está interesado en reconocer dentro de los códigos culturales (uno de ellos es el religioso) la gramática o sintaxis, cuya disposición de cuenta del lugar que ocupa cada componente de sentido, indicado por el orden que establece esa gramática o sintaxis. Dicha gramaticalidad profunda, cuyo fin es organizar el pensamiento humano en general, y no sólo el de los pueblos primitivos, hace que el hombre pueda ser considerado por Lévi-Strauss, como un animal simbólico. En tal sentido, el antropólogo agrega que el ser humano “(...) ha sido considerado como Homo faber, el hacedor de herramientas, y esta característica ha sido aceptada como la marca distintiva de la cultura humana. Confieso que no estoy de acuerdo y que uno de mis propósitos esenciales ha sido siempre mostrar que la línea de demarcación que separa la cultura de la naturaleza no es hacer herramientas sino articular discursos: Con el lenguaje se produce el salto adelante." (A.A.V.V., 1973: p. 58).

El planteamiento lévi-straussiano revela los verdaderos intereses investigativos del que es considerado como padre de la "antropología estructural". Su objetivo ya no es, como en el caso de Mauss, el de acercarse a la lingüística, como forma de superar las vaguedades analíticas en que habían incurrido tanto la sociología como la antropología. En tal sentido, Lévi-Strauss enfrenta directamente el desafío de articular un referente teórico basado en la lingüística estructural, para dar cuenta de esos elementos invariables de naturaleza profunda, que se encuentran en el pensamiento humano en general y en particular, en las racionalidades del hombre primitivo. De allí, su propuesta de una armature 
o armadura entendida como "(...) un conjunto no determinado de propiedades formales de orden sintáctico y / o semántico que se mantienen como invariantes (...)"(A. J. Greimas y C. Courtés, 1983: p. 40) dentro de un relato o discurso. La formalización de esta armadura o estructura profunda ocupa prácticamente todo el interés teórico de Lévi-Strauss. Tanto los mitos estudiados por este autor, como las diversas prácticas religiosas descritas, no son más que la selección de una materialidad significante que, como casuística, sirve para validar la propuesta formal de una estructura profunda de pensamiento, común a todos los hombres.

En este contexto teórico se debe apreciar el acercamiento de Lévi-Strauss al fenómeno religioso. Dicho fenómeno constituye una forma de lenguaje inserto en una red de relaciones estructurales existentes en un determinado tiempo y espacio. Este lenguaje religioso a su vez, sólo se puede entender, a partir de la interpretación que los miembros de la comunidad hacen de él, sobre la base de la experiencia y del conocimiento heredado de sus mayores.

En síntesis podemos señalar que la semántica antropológica de Lévi-Strauss se sitúa en un terreno propiamente semiótico. Como señala Rossi, respecto al trabajo de este antropólogo, “(...) se pasó a la perspectiva semiótica, según la cual el significado (o mejor, el valor) de un signo aparece determinado por su posición dentro de un sistema de relaciones."(Rossi, 1989: p. 100).

Según esta observación, Lévi-Strauss analiza la postura simbolista ya no a la manera en que la entendían Durkheim y Mauss, sino que de otra, puramente semiótica, que privilegia el concepto de signo por sobre el de símbolo. En efecto, la semiótica estructural francesa desarrollada a partir de los estudios de F. de Saussure, centra su objeto de estudio en la naturaleza lingüística de los signos entendiendo que el símbolo es una de las formas en que se expresan los signos. Por otro lado, delimitar el signo lingüístico como objeto de estudio permite, a partir de un conjunto de cuali- 
dades presentadas por éste, desarrollar una metodología descriptiva y explicativa que dé cuenta de esa naturaleza lingüística.

De este modo, el proyecto teórico de Lévi-Strauss se vuelca decididamente hacia un análisis estructural de diversos corpus discursivos, dentro de los cuales los mitos adquieren especial relevancia. En dicha actividad analítica, se intenta describir con la mayor rigurosidad posible, la armadura o estructura profunda que subyace a los sistemas lingüísticos que se intercambian en una comunidad o cultura.

Como señala el propio Lévi-Strauss, los sistemas lingüísticos o el lenguaje tanto mítico como religioso generan "(...) una imagen de mundo ya inscrita en la arquitectura del espíritu."(LéviStrauss, 1970: p. 188). Esta afirmación nos permite entender la intención final puesta en el análisis antropológico de origen estructuralista. Para Lévi-Strauss, el espíritu humano coincide con la matriz profunda de pensamiento que él formaliza. En tal sentido, dicho espíritu corresponde a una gramática específica que rige el orden del pensamiento, siendo el espacio desde el cual se generan las múltiples cadenas de sentido que finalmente organizan la vida social de los pueblos.

\section{Contribuciones a partir de la obra fundacional de M. Weber}

Para el desarrollo de esta tradición investigativa, la obra de Max Weber representa un referente fundamental, no sólo desde una perspectiva semiótica, sino que como un conjunto de reflexiones y proposiciones teóricas que dan cuenta de una visión sistemática y rigurosa sobre la estructuración de las sociedades humanas.

Al igual que Durkheim y Mauss, Weber concibe sus planteamientos teóricos dentro de un contexto epistemológico de corte positivista. Para comprender la visión que tiene Weber sobre la religión, es preciso tomar en consideración la concepción weberiana de la sociología. Según este teórico, la sociología debe ser 
entendida como “(...) una ciencia que busca la comprensión interpretativa de la acción social en orden a llegar a explicaciones de sus causas y efectos. En la 'acción' están incluidos todos los comportamientos humanos siempre que los actores les atribuyan significados subjetivos (...). La acción es social siempre que los significados subjetivos que le atribuyen los actores explique el comportamiento de otros, siempre que la acción se oriente para ese fin". (Weber, 1984a: p. 90).

Esta concepción de la sociología, implica que Weber estuviera consciente de que la comprensión interpretativa de los sistemas sociales representa dificultades para el propio proceso de conocimiento, ya que dicho proceso se enfrenta a expresiones subjetivas correspondientes a estados anímicos o situaciones de vida de las comunidades muy particulares e irrepetibles, como es el caso de los pueblos ágrafos, respecto de los cuales cualquier proceso de investigación se plantea desde un comienzo como limitado. En términos intencionales, al menos, Weber pretende superar las limitaciones impuestas por la actividad interpretativa de las sociedades, completando dicha actividad con un análisis causal, que provea de una explicación profunda respecto de los fenómenos en estudio. Esta intención orientada a la búsqueda de la causalidad de los hechos estudiados, marcadamente positivista, representa sólo eso, una intención, pues todos los trabajos emprendidos por la sociología respecto de los procesos sociales, se verán, de una u otra forma, sometidos a la dinámica de la actividad interpretativa de los fenómenos en estudio, todos ellos construidos sobre la base de estructuras de significación más simples o más complejas.

Planteado así el objetivo de la sociología, Weber mantiene presente a lo largo de toda su obra, la preocupación por el entendimiento del significado que los individuos de una sociedad asignan a los procesos mediante las cuales se genera y cambia una cultura. De este modo, la relación de causa y efecto planteada como motivo de estudio inicial, respecto del desarrollo de 
las sociedades, no se nos presenta como la cuestión fundamental que preocupa a este fundador de la sociología contemporánea. Su preocupación central es semiótica, y esto queda de manifiesto con claridad en cada temática tratada. Para Weber, el sentido de tópicos como el económico, el político y desde luego el religioso, constituye el objeto último de estudio de la sociología. La weltanschauung weberiana corresponde a la constitución de semiosferas culturales en donde los lenguajes utilizados y los contextos materiales y espirituales en que se desarrollan dichos lenguajes, forman un todo que debe ser intelegibilizado desde su materialidad sígnica.

A partir de estas consideraciones iniciales sobre la concepción que Weber entrega respecto a la función de la sociología, es posible adentrarse en el campo más específico relacionado con sus aportes sobre la religión y su sentido dentro de la sociedad. Para Weber, la sociedad occidental ha entrado en un proceso de racionalización progresiva en cuyo centro se encuentra el capitalismo entendido como un sistema económico que organiza racionalmente a los individuos con el fin de conseguir un beneficio económico por parte de los dueños del capital en desmedro de los asalariados.

Este proceso de racionalización significa, desde la perspectiva weberiana, una profunda desmistificación de la vida, de la conducta y la actitud de las personas. Según el autor, el Occidente moderno “(...) está caracterizado por la racionalización, el intelectualismo y, sobre todo por el 'desencanto' frente al mundo. Los valores más básicos y sublimes han desaparecido de la vida pública."(H.Gerth y C. Mills, 1987: p. 160).

Este diagnóstico es el que da forma al racionalismo pesimista que acompaña a Weber en todos sus trabajos, y desde el cual podemos aproximarnos a su comprensión de la religión.

A través del desarrollo de su particular sociología de la religión, señala que las formas más elementales de este fenómeno 
tienen que ver con cuestiones de naturaleza práctica en torno a la vida trivial de los miembros de una comunidad. De este modo “(...) el comportamiento (...) religioso no debe ser tratado aparte de la conducta intencional cotidiana, especialmente teniendo en cuenta que los fines de los actos religiosos (...) son predominantemente económicos (...)."(Weber, 1984a: p. 1). En este contexto, la práctica de rituales y celebraciones en general, cuyo referente es un ser sobrenatural o elemento material concreto, cumple una función básicamente práctica, orientada a la producción de cosechas abundantes, o a la preservación de la salud para la vida del trabajo comunitario.

En la perspectiva de Weber, la religión cumple una función cohesiva, mediante la cual los miembros de una familia o clan se congregan. La unidad obtenida por estos grupos comunitarios obedece fundamentalmente "(...) a la relación que les une con los espíritus de los ancestros (...)."(Weber, 1984a: p. 10). Dentro de las sociedades primitivas, los individuos encargados de establecer las vinculaciones entre la comunidad y dichos espíritus ubicados en dimensiones sobrenaturales, poseían poderes y talentos que podrían ser traducidos como hipersensibilidades especiales, o dones a partir de los cuales se practicaban un conjunto de ritos vinculantes entre los hombres y los espíritus que de una u otra forma regían la vida individual y comunitaria de un grupo. Según Weber, el proceso de racionalización propio de la modernidad reemplazó a estos sujetos que ejercían un rol mediador entre lo humano y lo suprahumano mediante “(...) la sistematización de principios racionales impulsada por el racionalismo de los sacerdotes profesionales o por un deseo de orden por parte de los seglares."(Weber, 1984a: p. 22). Dichos profesionales de la religión (o sacerdotes) formarían parte, especialmente dentro del cristianismo, de un proceso de "(...) difusión creciente de una comprensión racional del cosmos como un todo ordenado y eterno." (Weber, 1984a: p. 35). Así, el sacerdocio funciona como el símbolo de la racionalización y de la sistematización de la cultura religiosa moderna. 
Contribuciones de la sociología y la antropología para la comprensión del fenómeno religioso: una lectura en clave semiótica - Jorge Brower Beltramin

En contraposición a esta funcionalidad del sacerdocio en el contexto de las sociedades modernas, Weber hace notar el carisma que debían poseer los individuos que, dentro de las sociedades primitivas, realizaban las prácticas rituales en torno a lo sobrenatural. En tal sentido, el carisma es entendido como "(...) ciertas cualidades de la personalidad de un individuo, de forma que es visto como diferente del resto de hombres normales, y al que se le atribuyen poderes o cualidades sobrenaturales, sobrehumanas o, como mínimo, particularmente excepcionales."(Weber, 1984b: p. 358).

Desde una perspectiva semiótica, el alcance conceptual realizado por Weber respecto al carisma, resulta particularmente interesante, ya que las cualidades carismáticas constituyen un conjunto de potencialidades interpretativas, a través de las cuales, a ciertos individuos, les era posible comprender el sentido último de un cosmos construido mediante trazos complejos de significación. En tal dirección, profetas, héroes, chamanes y sabios constituyen una clase de individuos con capacidades interpretativas superiores al resto de los miembros de una comunidad. En el caso particular de los profetas, estos “(...) sistematizaban el contenido de la profecía o las tradiciones sagradas por medio de una estructura de análisis casuístico y racionalista, adaptándolas a las costumbres de vida y pensamiento de su propia clase y del laicado al que controlaban." (Weber, 1984a: p. 69).

La actividad interpretativa de estos sujetos revela las capacidades propias que requiere cualquier proceso complejo de interpretación dentro de una semiosfera cultural, en la que, sin duda, se incluye el campo semántico de lo sobrenatural donde los dioses ocupan un lugar central. Sin embargo, y como ya hemos señalado, para Weber esta conexión con lo sobrenatural no apuntaba, en las sociedades primitivas, a formas de conocimiento más profundo de sus dioses, sino que tenía como finalidad la resolución de temas prácticos y mundanos. De este modo, los valores sagrados de estas sociedades tenían que ver con bienes primarios tales como la salud, la longevidad y la riqueza material. 
En síntesis, la sociología planteada por Weber, construye una perspectiva de análisis que descansa en la tesis de que el hombre, a través de la religión, busca establecer un orden cósmico significativo, es decir, un kosmos que satisfaga su necesidad de significado. En ese sentido, la religión entendida como componente fundamental para la articulación de una cultura, puede ser concebida como el eje central en torno al cual las sociedades ágrafas establecían sus formas de vida. Por otro lado, en el contexto de la sociedad occidental moderna, Weber describe con notable sentido analítico el desplazamiento de estas prácticas religiosas primitivas, y la consiguiente instalación de nuevas formas religiosas en consonancia con el proyecto global de la modernidad.

Dentro de los teóricos que retoman la sociología fundada por Weber, los trabajos de A. Schütz representan un aporte relevante desde la perspectiva semiótica asumida en nuestra tesis. Aun cuando Schütz no orienta su trabajo hacia una sociología de la religión, retoma la obra de Weber, para delimitar con mayor rigurosidad las características de la actividad interpretativa de los sujetos sobre diversos sistemas semióticos al interior de una cultura.

Dentro de ese contexto teórico, nos parece pertinente revisar algunos planteamientos fundamentales realizados por Schütz, con el fin de poder entender con mayor claridad la forma en que autores posteriores, tales como P. Berger y C. Geertz, construyen una perspectiva teórica para comprender la función que cumple la religión en las sociedades.

En primer término, Schütz advierte que el objeto de estudio de la sociología, siempre corresponde a fenómenos de construcción de significado, cuyo origen es un conjunto de temores, expectativas y esperanzas que el investigador jamás podrá reconstruir de manera fiel. En ese escenario, los miembros de la comunidad que han elaborado las pautas culturales, son considerados cada uno de ellos como "(...) un actor situado dentro del mundo social (...)"(Schütz, 1999: p. 54), que experimenta como propias el con- 
junto de sus acciones significativas a partir de una pauta de sentido cultural compartido. Planteadas de esta forma las condiciones en que la sociología se aproxima a los fenómenos que desea comprender, esta disciplina podrá obtener un conocimiento graduado de los elementos significativos que dan forma a una cultura. Mientras mayor sea el espesor de la significatividad captada por el sociólogo en relación a una cultura específica, mayor será el grado de conocimiento que se tenga respecto de esa cultura.

En esta dinámica de comprensión, el mundo cultural aparece "(...) en todo momento como estratificado en diferentes capas de significatividad cada una de las cuales exige un grado diferente de conocimiento."(Schütz, 1999: p. 55). Con esta afirmación, Schütz establece dos preocupaciones que serán fundamentales en todos sus trabajos teóricos. Por una parte explicita su concepción del mundo cultural como un conjunto de niveles de sentido, unos más complejos que otros. Por otro lado, plantea que la comprensión real de la cultura tiene que ver con el conocimiento de ciertas claves propias de la producción del sentido social y de la interpretación de las mismas.

Frente al proceso de producción y reproducción cultural, Schütz es consciente de la gran inestabilidad a la que es sometido tal proceso señalando al respecto que "(...) la continua modificación de los intereses produce una transformación ininterrumpida de la forma y densidad de los perfiles de significatividad."(Schütz, 1999: p. 56). En efecto, las vinculaciones significativas entre los miembros de un grupo, no sólo varían a partir de los intereses del propio grupo, sino que también se ven afectadas por el contacto natural con otras atmósferas culturales o semiosferas, generando en esa situación una convivencia muchas veces no prevista, en la que trazos de sentido se desplazan entre los grupos involucrados, exigiendo con ello, un conjunto de procesos de lectura, interpretación y adaptación que de una u otra forma desestabilizan los proyectos internos de cada sociedad. En este proceso de lectura, interpretación y adaptación del sentido, Schütz plantea 
la existencia de un conjunto de factores que en definitiva determinan la validez de las acciones interpretativas de los individuos al interior de una cultura. Los esquemas desarrollados para la interpretación cultural se actualizan mediante estructuras lingüísticas que están conectadas a su vez con campos discursivos ya instaurados en las bases de la cultura, y que funcionan como referentes obligados para la elaboración de nuevos contenidos. Por otro lado, este teórico señala que el universo discursivo en su conjunto, está circundado por "(...) un halo de valores emocionales e implicaciones irracionales que son, en sí mismos, inefables." (Schütz, 1999: p. 57). La explicitación de esta especie de residuo del significado, en directa relación con la producción del mismo, lleva a Schütz al planteamiento de que la sociología, en tanto que aproximación comprensiva de la cultura, entendida como un mundo fundamentalmente semántico, debe considerar el conocimiento obtenido como parcial y siempre inacabado.

Pero el lenguaje no sólo está conectado con otros campos también lingüísticos, propios del repertorio de una cultura, asociados a estados emocionales poco aprehensibles, sino que también la naturaleza connotativa de la materialidad lingüística se vincula estrechamente con las condiciones contextuales en que esa materialidad se produce. En los términos de Schütz, adicionalmente a las connotaciones generales y estandarizadas de un lenguaje específico, existe "(...) un significado secundario especial, derivado del contexto o el ambiente social dentro del cual se lo usa, y recibe, además, un matiz especial producido por la ocasión concreta en que se lo emplea."(Schütz, 1999: p. 57). La indagación analítica propuesta por este investigador, como objetivo de la sociología, advierte de manera muy lúcida sobre el sentido de las estructuras sociales, entendido como un todo en el que los lenguajes se conectan fluidamente con los contextos de producción de las estructuras significativas.

Finalmente, Schütz observa en relación a este estrecho contacto entre discurso y situación de la producción discursiva, el 
Contribuciones de la sociología y la antropología para la comprensión del fenómeno religioso: una lectura en clave semiótica - Jorge Brower Beltramin

carácter personal, a través del cual cada individuo actualiza sus competencias lingüísticas. En tal dirección agrega que dentro de un grupo, por reducido que este sea, los participantes del mismo poseen un "(...) código privado, comprensible únicamente para aquellos que han participado en las experiencias pasadas comunes en las que surgió o en la tradición vinculada con ella."(Schütz, 1999: p. 57). ${ }^{7}$

El conjunto de factores mencionados diseña los esquemas interpretativos y/o productores de sentido, mediante los cuales interactúan los miembros de una cultura. Por tanto, y desde la perspectiva sociológica asumida por Schütz, sólo los participantes de ese grupo dominarán realmente los esquemas de expresión más pertinentes, ya que son utilizados de manera habitual, sin necesidad de analizar sus componentes, actividad que sí es propia de la sociología.

En definitiva, el aporte de Schütz se sitúa en un nivel epistemológico que pretende dar forma a una teoría general del conocimiento entendido como una construcción compleja de sentido.

Es en este contexto de producción de una teoría del conocimiento, en donde se inscribe la obra de P. Berger, quien, desde los postulados de Schütz, concibe una teoría sociológica de la religión. Para desarrollar los planteamientos fundamentales de esta sociología de la religión es que optamos por exponer previamente algunas de las claves del pensamiento de Schütz, sin las cuales las investigaciones de Berger carecerían del sustento conceptual

7 Nos parece importante destacar que estas últimas observaciones teóricas realizadas por Schütz en relación a los factores que condicionan el sentido del lenguaje al interior de una cultura, se acercan a los postulados que plantea la semiótica pragmática dentro de la tradición peirciana.

Sobre esta última nota, referida al uso de códigos muy particulares por parte de los miembros de un grupo para expresarse lingüísticamente, la actividad productora de sentido se aproxima de manera notable al concepto que los lingüistas en general denominan "idiolecto". Por tal denominación se entiende "(...) la actividad semiótica productora y/o lectora de las significaciones -o del conjunto de textos relativos a ellapropia de un actor individual que participa de un universo semántico dado." A.J. Greimas y J. Courtés, Semiótica. Diccionario razonado de la teoría del lenguaje, p. 214. 
necesario que, en definitiva, explica su aporte en torno a la comprensión del fenómeno religioso dentro de la cultura.

Los esfuerzos teóricos de Berger se orientan más bien a la comprensión de la religión dentro de una sociología del conocimiento en la que se privilegia el valor de la religión entendida como uno de los componentes de sentido que dan forma a un mundo cultural.

Con el fin de comprender la función que cumplen las prácticas religiosas en una sociedad, Berger realiza un conjunto de consideraciones generales respecto a ciertas características del proceso de construcción social de la realidad. En tal sentido está consciente de la dinámica cambiante de las sociedades y las culturas. Al respecto señala: "La cultura tiene que ser continuamente producida y reproducida por el hombre. Sus estructuras son, pues, intrínsecamente precarias y predestinadas a los cambios." (Berger, 1999: p. 19). En la perspectiva de este autor, buena parte de la precariedad de las estructuras culturales obedece a que su construcción se basa en el lenguaje, instrumento mediante el cual se da forma a "(...) un edificio de símbolos que animan todos los aspectos de la vida."(Berger, 1999: p. 19). Estos símbolos cambian porque los sujetos en el proceso de desarrollo cultural también cambian o modifican sus concepciones de realidad. El mundo simbólico construido, según Berger, no es más que un ordenamiento de la experiencia del hombre, ordenamiento que se establece mediante relaciones de sistemas de significación coherentes para un grupo en un momento determinado. Como consecuencia de este proceso, es el lenguaje el que expresa dicho orden, imponiendo una estructuración al flujo caótico de la experiencia. Al respecto, este investigador agrega: "Cuando un elemento de la experiencia recibe un nombre es, ipso facto, retirado del fluir y adquiere estabilidad como una entidad así nombrada."(Berger, 1999: p. 19).

En definitiva, para este autor, la construcción de la realidad, mediante el lenguaje, permite que “(...) se levante el gran edificio 
Contribuciones de la sociología y la antropología para la comprensión del fenómeno religioso: una lectura en clave semiótica - Jorge Brower Beltramin

cognoscitivo y normativo que en una sociedad se considera 'conocimiento'." (Berger, 1999: p. 39). En otras palabras, para Berger, el lenguaje cumple la doble función de construir el mundo social y además ser el instrumento mediante el cual podemos conocer ese mundo por medio de metalecturas sucesivas, haciendo en lo posible, que el espesor significativo de cada una de esas lecturas nos entregue mayor comprensión sobre el funcionamiento de una cultura.

A partir de estas consideraciones, Berger entra de manera directa a la comprensión de la religión entendida como uno de los componentes de sentido que ayuda a ordenar el mundo social. Como señala el propio autor: "Religión es la empresa humana por la que un cosmos sacralizado queda establecido. Dicho de otro modo, religión es una cosmización de tipo sacralizante. Por sagrado entendemos aquí un tipo de poder misterioso e imponente, distinto del hombre y sin embargo relacionado con él, que se cree que reside en ciertos objetos de experiencia."(Berger, 1999: pp. $46-47){ }^{8}$

Para este autor, la religión ocupa un lugar central en el ordenamiento del mundo construido por el hombre. A través de los diversos componentes de sentido religioso, los individuos van situando su existencia dentro de un orden que aporta la significatividad definitiva de cualquier proyecto humano y por tanto social y cultural. En dicha construcción de sentido, ciertamente muy compleja, pues debe explicar el telos de la actividad de un grupo en todas sus dimensiones, incluyendo el nacimiento y la inexorable instancia de la muerte de cada uno de los que participa de una misma visión de mundo o cosmovisión, individuos y espacios definidos deben adquirir cualidades superiores a las

8 Es necesario destacar que Berger coincide con el conjunto de autores tratados, respecto a la función predominantemente ordenadora del mundo social, cumplida por la religión. Del mismo modo, al calificar la religión como una empresa, este autor quiere enfatizar que se trata de una manifestación empírica, observable y por tanto describible, a través de sus prácticas concretas, como lo son los rituales y ceremonias en general. 
habituales con el fin de poder realizar con éxito una vinculación con el mundo sobrenatural y los elementos que, dentro de ese mundo, pueden favorecer el desarrollo de una comunidad.

Planteada la religión de este modo, como una actividad ordenadora de la vida social, Berger da un paso más en su argumentación, señalando que esta cosmización sagrada constituye un orden superior al cual se opone el caos y por tanto, el sinsentido que inevitablemente conduce al hombre y su cultura a la destrucción. En esa dirección, agrega que el cosmos sagrado instaurado por la religión “(...) que trasciende e incluye al hombre en su ordenación de la realidad, le provee así de un último escudo contra el terror anómico." (Berger, 1999: p. 48) El cosmos proporcionado por la religión constituye el nomos u orden fundamental que regla o norma la conducta de los individuos al interior de una cultura. De esta forma, el nomos religioso se convierte en la ley que rige todas las leyes, el fundamento que explica todas las prescripciones, que autoriza ciertas conductas y rechaza otras invocando el bien superior de todos los congregados por una creencia.

Para construir estos mundos nómicos sagrados capaces de anular el terror al caos de un mundo sin reglas, los individuos deben permanecer en un estado constante de exteriorización de sentido, mediante la producción de sistemas semánticos codificados y compartidos que permitan la estabilidad de la cultura entendida como un espacio semiótico capaz de contener altos niveles de significatividad, sin perder de vista los objetivos trazados y las acciones que estos objetivos implican. Para Berger, la sociedad humana asume la trabajosa tarea de construir "(...) un edificio de significados exteriorizados y objetivados, siempre persiguiendo la consecución de una totalidad significativa." (Berger, 1999: p. 49). En esta tarea, la construcción de un universo de sentido religioso, representa una actividad trascendente, en la medida en que dicho universo desarrolla un explicandum que abarca la existencia humana en todos sus aspectos, siendo los más significativos, ciertamente, la explicación de la vida y la muerte. 
Como hemos expuesto hasta aquí, dentro de la empresa global de construcción del mundo social, el nomos religioso representa, sin duda, la producción semiótica de mayor trascendencia realizada por el hombre.

Para Berger, a su vez, la "(...) religión implica que el orden humano sea proyectado en la totalidad del ser." (Berger, 1999: p. 50). De allí, la complejidad de este sistema entendido como universo simbólico, pues constituye un intento superior de la capacidad expresiva del hombre, por concebir el cosmos en su totalidad, más allá de los umbrales de las diversas construcciones culturales, como humanamente significativo, o humanamente expresable y nominable, poniendo el sello de lo esencialmente humano en un territorio cósmico sobre el cual no podemos decir nada realmente significativo.

$\mathrm{Al}$ avanzar sobre las reflexiones hechas por Berger respecto a la función que realiza la religión dentro de la construcción social de la realidad, vemos que su cualidad normativa y explicativa no sólo se proyecta hacia una dimensión cósmica global y más intangible, sino que, como hemos apuntado antes, fundamenta y rige también la vida cotidiana de los seres humanos. En su estatus de realidad sagrada, la religión se instala discursivamente más allá de cualquier contingencia producida por la interacción de los hombres, entregando de esta forma las directrices de comportamiento que legitiman o deslegitiman las acciones emprendidas por los sujetos o las instituciones desde las que se desarrolla la vida social. De este modo, la función legitimadora de la religión representa un acto fundamental ya que implica otorgar un sentido cósmico y sagrado a las acciones y obras puramente humanas. $\mathrm{Al}$ respecto, este investigador señala que la importancia de la legitimación religiosa "(...) se explica por su capacidad única de localizar los fenómenos humanos dentro de un marco de referencia cósmico."(Berger, 1999: p. 60).

La validación religiosa de las acciones y obras emprendidas por el hombre permite que éstas adquieran mayor trascendencia 
en el tiempo, asegurando su funcionamiento y reforzando simultáneamente su credibilidad dentro de un grupo o comunidad. Como consecuencia de lo anterior, podemos señalar con Berger, que la legitimación religiosa atraviesa el orden social completo, entregando una regulación sagrada a todos los nomoi o reglas elaboradas para encauzar las acciones humanas. Dicho de otro modo, los diversos ámbitos desarrollados por el hombre para la vida social se ven sometidos a una interpretación significativa, aportada por el componente religioso de la cultura.

Al describir de este modo la función de la religión dentro de la construcción del mundo cultural, el autor insiste en definirla como "(...) el establecimiento, a través de la actividad humana, de un orden sacro que lo abarca todo, es decir, de un cosmos sagrado capaz de mantenerse siempre presente frente al caos." (Berger, 1999: p. 177). De esta forma, el nomos religioso, al que ya nos hemos referido, posee un poder ordenador de la sociedad, confiriendo un sentido último y definitivo a la vida. La teodicea o explicación más o menos racional aportada por la religión, en relación a todos los aspectos de la existencia, ofrece un verdadero programa semántico o ruta, por la cual deben transitar los seres humanos. Allí radica su valor o importancia sustantiva y no en los contenidos particulares que siempre se encuentran al servicio de ese programa básico y fundamental.

Toda teodicea, más allá de la cultura en la que ha sido concebida y desarrollada, tiene como objetivo el conservar el mundo construido, ocupando en esta actividad de conservación un lugar central. Su motivación más profunda, enfatiza Berger, es la de mantener a raya la presión de las fuerzas caóticas que provienen de dos ámbitos distintos. Por una parte, el orden sagrado ayuda a repeler el caos propio de un mundo natural que muchas veces no comprendemos y por otra, permite realizar una suerte de pacto con la muerte, expresión definitiva del caos que se establece como horizonte permanente del orden biológico y cultural del hombre. Sobre la muerte, entendida como estado caótico defini- 
tivo, la teodicea intentará encontrar significaciones que permitan al hombre instalarse dentro del fluir de la existencia muchas veces hostil, sin caer en el pánico del sinsentido que el horizonte de muerte le recuerda de manera constante.

En síntesis, para Berger, la religión ha constituido, dentro de la historia de las culturas, una de las formas más importantes de ideología en el sentido de que lo sagrado funciona, básicamente, como una modalidad esencial para configurar el mundo, conduciendo empíricamente la actividad humana, mediante un proceso de producción discursiva que, como hemos señalado, ordenando el quehacer del hombre en la cultura, le permita también proyectarse más allá de su vida terrenal. En tal sentido, el propio Berger agrega que la proyección de significaciones en la vacía amplitud del universo, termina revirtiéndose sobre sus productores en forma de realidad de orden trascendente. Es el hombre finalmente, quien interpela al cosmos silencioso, en un diálogo que no es sino consigo mismo, generando toda una trama de sentido, todo un relato que revela la búsqueda humana de la significación de su propia existencia.

A partir de los planteamientos para el desarrollo de una sociología interpretativa, planteados por autores como Schütz y Berger, C. Geertz incorpora en el campo de la antropología, la comprensión interpretativa de la cultura, dentro de la cual, la religión será entendida como el locus del significado, es decir, como la construcción de sentido fundamental en la vida del hombre.

Para comprender con mayor profundidad las afirmaciones de Geertz respecto de la religión, es necesario revisar su concepción más amplia de la cultura, cuestión que, en términos generales, es lo que le interesa a su antropología semántica o interpretativa.

Para Geertz, la cultura debe ser entendida en este contexto disciplinar (antropología) como un fenómeno “(...) esencialmente semiótico, creyendo con Weber, que el hombre es un animal inserto en tramas de significación que él mismo ha tejido, (...), 
la cultura es esa urdimbre y el análisis de la cultura ha de ser por tanto, no una ciencia experimental en busca de leyes, sino una ciencia interpretativa en busca de sentidos."(Geertz, 1994: p. 24). En esta primera aproximación a la cultura entendida desde su naturaleza semiótica, quedan en evidencia, en primer lugar, su relación teórica con la obra de Weber y en segundo término, su desvinculación definitiva con los presupuestos del paradigma positivista. La antropología, al igual que la sociología, no pueden ser comprendidas como ciencias experimentales de orden puramente empírico, sometidas a una lógica causalista que explica los hechos siempre del mismo modo, aunque las condiciones de producción de esos hechos cambie.

De este modo, Geertz asume de manera explícita y formal una postura teórica para la antropología, que reúne y sintetiza los aportes de Schütz y Berger. A partir de los trabajos de Geertz, la antropología interpreta la cultura como una trama de sentido, y al hacerlo, construye otra trama también semiótica. El conocimiento antropológico se expresa como una construcción de significado, a través del lenguaje, construcción ciertamente subjetiva e intersubjetiva, ya que involucra en su proceso de producción, al antropólogo, al corpus semántico analizado y a los sujetos que dan vida a dicho corpus cultural. En tal dirección reflexiva, el pensamiento de una sociedad, de una cultura “(...) es una cuestión relativa al tráfico de formas simbólicas disponibles en una u otra comunidad (lenguaje, arte, mito, teoría, ritual, tecnología, (...)" (Geertz, 1994: p. 90). Frente a ese tráfico de formas simbólicas, el antropólogo produce un tipo de conocimiento que "(...) en un sentido amplio es tan poético como ficcional (...)" (Geertz, 1997: p. 100).

A partir de esta concepción general de la cultura y del tipo de conocimiento al que puede aspirar la antropología, Geertz propone que el trabajo antropológico debe consistir en una descripción densa de las estructuras más significativas de los cuerpos culturales estudiados. El autor señala que dicha descripción densa 
Contribuciones de la sociología y la antropología para la comprensión del fenómeno religioso: una lectura en clave semiótica - Jorge Brower Beltramin

da cuenta de "(...) una multiplicidad de estructuras conceptuales complejas, muchas de las cuales están superpuestas o enlazadas entre sí, estructuras que son al mismo tiempo extrañas, irregulares, no explícitas, y a las cuales el antropólogo debe ingeniarse de alguna manera, para captarlas primero y para explicarlas después." (Geertz, 1994: p. 102). Como es posible observar, la aproximación comprensiva a la cultura, propuesta por Geertz, se caracteriza por la densidad o complejidad de las estructuras semánticas que se ponen en contacto para dar forma a la trama global que da cuenta de una cosmovisión cultural. Este antropólogo está consciente de la variedad morfológica de los diversos bloques de sentido que se van ligando en la dinámica de producción cultural. Frente a esta interconexión y diálogo, entre códigos provenientes de atmósferas culturales de naturalezas muy diferentes, el antropólogo debe ser capaz de delimitar dichos componentes de sentido para explicar cómo funcionan, señalando cuál es su importancia específica y funcionalidad semántica dentro del proceso siempre inacabado de desarrollo cultural.

La descripción densa expuesta por Geertz, corresponde en definitiva, a la constitución teórica de un agente-intérprete que, mediante la activación de un conjunto de competencias lingüísticas y translingüísticas, es capaz de dar cuenta del funcionamiento de las estructuras básicas de una cultura.

De este modo, sus planteamientos, en relación a la naturaleza de la cultura, dan forma a una antropología semántica que asume la descripción y explicación de la religión como el sistema más complejo de significados elaborado por el hombre. Sobre este fenómeno en particular (la religión), Geertz propone que es un sistema esencialmente cultural que proporciona sentido a toda la existencia humana, definiéndola como “(...) un sistema de símbolos que imprime a los hombres de forma poderosa y duradera un carácter y una motivación a través de la formulación de concepciones referentes a un ordenamiento general de la existencia, concepciones que están revestidas con un aura tal de realidad 
que las actitudes y motivaciones parecen singularmente verídicas." (Geertz, 1994: p. 90).

A través de esta afirmación, Geertz, nos da a entender que el sistema de símbolos que configura una religión, constituye una red básica de sentido altamente congruente y poderosamente explicativa de la realidad. Al igual que lo señalado por Berger, la función de dicha matriz simbólica básica, se orienta a establecer un ordenamiento de la vida social en su integridad. Así, lo que con Berger llamábamos nomos u orden del mundo cultural, se expresa, a través de la postura geertziana, como la existencia de un conjunto de símbolos que, al entrar en un proceso de interacción, entregan un estilo de vida y una metafísica específica, dando forma a un cosmos totalizante y armónico que en definitiva expresa el ethos de un pueblo. Dicho ethos contiene las cualidades de la vida propuesta y sus conceptos fundamentales respecto al orden social. Así, el cosmos religioso, constituido por una extensa red discursiva que contiene las creencias por las cuales el hombre debe regir su vida, entrega explicaciones para todos los acontecimientos y experiencias que tengan relación con el devenir de la existencia humana, y que de una u otra forma pongan esa existencia a salvo, frente al peligro del caos que, como ya hemos señalado, se mantiene siempre latente como elemento que provoca inestabilidad al interior del trazado normativo instaurado por la cultura. Para Geertz, es precisamente este conjunto de símbolos religiosos el que ofrece al hombre una dimensión trascendente de la existencia para anular la intervención del caos, entendido como "(...) un cúmulo de acontecimientos que carecen, no ya de interpretaciones sino de interpretabilidad."(Geertz, 1994: p. 100). Al hacer este planteamiento respecto al caos, Geertz lo sitúa en la frontera que conecta con situaciones como la confusión extrema, el miedo y las paradojas, cuestiones que en la existencia más común y trivial del hombre suceden, atentando contra el orden y el sentido que ofrece la religión. A partir de la forma en que se asumen los estados de caos vs cosmos, los conceptos religiosos realizan la doble función de conectar al hombre con una dimen- 
Contribuciones de la sociología y la antropología para la comprensión del fenómeno religioso: una lectura en clave semiótica - Jorge Brower Beltramin

sión de la existencia más allá de la vida terrenal y por otro lado, entregan las pautas valóricas y normativas mediante las cuales se deben regir los individuos en una sociedad. En los términos de Geertz, la religión “(...) no se restringe a un contexto meramente metafísico, proporciona una estructura de ideas a través de las cuales una amplia serie de experiencias -intelectuales, emocionales, morales- cobra significado." (Geertz, 1994: p. 102).

En síntesis, para este autor, la comprensión del fenómeno religioso y su correspondiente funcionalidad se desplaza entre las cuestiones relativas a la vida cotidiana y las preocupaciones más profundas del ser humano, relacionadas al sentido de su existencia y de la muerte. Sobre este amplio espectro de temáticas, las formas simbólicas religiosas cumplen la función de dar coherencia a todas ellas, mediante un relato que explica y vincula cada uno de los temas propios de lo humano.

Como hemos podido comprobar en la exposición de estos contenidos provenientes de las tradiciones disciplinares articuladas en torno a la sociología y la antropología, desde el planteamiento formal de estas disciplinas existe una preocupación constante por la naturaleza sígnica de la cultura y en particular, por la expresión figurativo-simbólica de lo religioso. Al respecto, sociólogos y antropólogos se aproximan conceptualmente a la religión desde cierta conciencia semiótica que se constituye en un referente teórico-comprensivo de gran importancia para llevar a cabo cualquier forma de análisis semántico dentro del ámbito disciplinar semiótico. De este modo, creemos que dichos análisis se hacen cargo de una exigencia planteada por la sociología y la antropología en relación a la posibilidad de dar cuenta formal de los contenidos sobre los cuales se articula la expresión de lo religioso. Así, la descripción socio-antropológica, se ve completada por el dispositivo analítico semiótico, que explica o debe explicar de mejor forma la organización de los contenidos mediante los cuales se expresa culturalmente la religión, gracias a la reflexión y producción de conocimiento sociológico y antropológico. Fi- 
nalmente, la explicación semiótica se enriquece pues dimensiona en el contexto mayor de la cultura, las estructuras profundas y de superficie por medio de las cuales la religiosidad de un pueblo se hace materialidad significante.

\section{Bibliografía}

A.A.V.V. (1973). Estudios sobre estructuralismo, Buenos Aires, Tiempo Contemporáneo.

Berger, P. (1999). El Dosel Sagrado. Para una teoría sociológica de la religión, Barcelona, Kairos.

Durkheim, E. (1982). Las formas elementales de la vida religiosa, Madrid, Akal.

Geertz, C. (1990). La Interpretación de las Culturas, Barcelona, Gedisa.

(1994). Conocimiento Local. Ensayos sobre la interpretación de las culturas, Barcelona, Paidós/Básica. (1997).El antropólogo como autor, Barcelona, Paidós/Básica.

Gerth, H. y Mills, C. (1987). Ensayos de Sociología. M. Weber, Barcelona, Labor.

Greimas, A.J. y Courtés, C. (1983). Semiótica. Diccionario razonado de la teoría del lenguaje, Madrid, Gredos.

Lévi-Bruhl, L. (1947). Las funciones mentales en las sociedades inferiores, Buenos Aires, Lautaro.

(1972). La mentalidad primitiva, Buenos Aires, La Pléyade.

Lévi-Strauss, L. (1992). Antropología Estructural, Barcelona, Paidós.

Mauss, M. (1991). Sociología y Antropología, Madrid, Tecnos.

Pritchard, E. (1980). Ensayos de Antropología Social, Madrid, Siglo XXI.

Rossi, A. (1989). De la Sociología de los Símbolos a la Sociología de los Signos, Madrid, Tecnos.

Schütz, A. (1999). Estudios sobre Teoría Social, Buenos Aires, Amorrortu.

Weber, M. (1984a). Ensayos sobre sociología de la religión, Madrid, Taurus. (1984b). Economía y Sociedad, Madrid, Taurus. 